\title{
Anika Klafki
}

\section{Risiko und Recht}

Risiken und Katastrophen im Spannungsfeld von Effektivität, demokratischer Legitimation und rechtsstaatlichen Grundsätzen am Beispiel von Pandemien

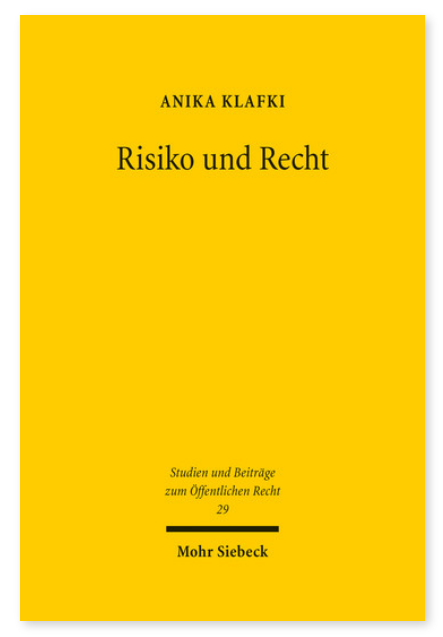

2017. XXIX, 438 Seiten. StudÖR 29

ISBN 978-3-16-155051-5

DOI 10.1628/978-3-16-155051-5

eBook PDF $109,00 €$
Risiken bezeichnen zukünftige Schadensereignisse, deren Eintrittswahrscheinlichkeit und Folgenschwere ungewiss sind. Daraus ergeben sich besondere Herausforderungen an das Recht. Anhand der Bewertungsparameter Effektivität, demokratische Legitimation und rechtsstaatliche Grundsätze entwickelt Anika Klafki konkrete Maßgaben für die Risikoregulierung im Mehrebenensystem. Dabei tritt sie sowohl technokratischen Ansätzen, die externen Sachverständigen die Regelungsaufgabe überlassen wollen, als auch autokratischen Bestrebungen, die im Angesicht von Katastrophen exekutive Stellen weiträumig ermächtigen möchten, entgegen. Anhand von Pandemien als dynamischen Katastrophen zeigt sie, dass der rechtswissenschaftliche Fokus auf die Risikoprävention zu eng ist. Vielmehr müssen auch die Katastrophenvorbereitung und -bekämpfung sowie die Risiko- und Katastrophenkommunikation regulativ mitbedacht werden, um ein zeitgemäßes Sicherheitsrecht zu gewährleisten.

Die Arbeit wurde mit dem Wissenschaftspreis der Gesellschaft für Recht und Politik im Gesundheitswesen 2017 und dem Promotionspreis der Bucerius Law School 2017 ausgezeichnet.

Anika Klafki Geboren 1986: Studium der Rechtswissenschaft an der Bucerius Law School in Hamburg und der University of Queensland in Australien; Referendariat in Hamburg, Istanbul und Marseille; wissenschaftliche Mitarbeiterin an der Bucerius Law School; 2014/2015 Lehrbeauftragte an der Universität Sarajevo; 2016 Promotion; seit 2016 wissenschaftliche Assistentin und Habilitandin am Lehrstuhl für Öffentliches Recht bei Prof. Dr. Hermann Pünder, LL.M. an der Bucerius Law School.

Jetzt bestellen:

https://mohrsiebeck.com/buch/risiko-und-recht-9783161550515?no_cache=1

order@mohrsiebeck.com

Telefon: +49 (0)7071-923-17

Telefax: +49 (0)7071-51104 